\title{
Research on Mechanical Characteristic of Weak Surrounding Rock Large Span Double and Multi-Arch Tunnel Construction
}

\author{
Junfu $\mathrm{Lu}^{1,2,3, *}, \mathrm{Yu} \mathrm{Yu}{ }^{1}$ and Xun Wang ${ }^{1}$
}

\author{
${ }^{1}$ China Railway Eryuan Engineering Group Co. Ltd, Chengdu 610031, China; ${ }^{2}$ State Key Laboratory of Geohazard \\ Prevention and Geoenvironment Protection, Chengdu University of Technology, Chengdu 610059, China; ${ }^{3}$ School of \\ Civil Engineering, Southwest Jiaotong University, Chengdu 610031, China
}

\begin{abstract}
According to construction scheme of some weak surrounding rock large span double and multi-arch tunnel works, finite element value simulation method is adopted to research weak surrounding rock deformation characteristic, anchor bolt mechanics characteristic, preliminary support and secondary lining structure mechanical characteristics, etc, and the research result shows that: repeatedly disturbance of excavation of middle pilot tunnel and subsequent supporting excavation shall easily reduce surrounding rock strength in the range of middle wall top and middle line of arch top of left and right pilot tunnels, therefore, prior to excavation of middle pilot tunnel, surrounding rock of tunnel top shall be pregrouting reinforced to improve integrated strength of surrounding rock of arch top, max. Accumulated settlement displacement of tunnel is $19.45 \mathrm{~mm}$, max. Horizontal convergence displacement of side wall of left and right tunnel is 9.71 $\mathrm{mm}$, max. Vertical upheaval displacement of middle wall bottom is $8.82 \mathrm{~mm}$, above displacement can all be within controlled range satisfying design requirement; max. plastic zone vertical depth of upper side of left and right tunnel arch top is respectively $1.23 \mathrm{~m}$ and $2.06 \mathrm{~m}$, inverted arch bottom plastic zone vertical depth is $2.74 \mathrm{~m}$ and $3.37 \mathrm{~m}$, radial depth of middle plastic zone of side wall of left and right tunnel is respectively $0.87 \mathrm{~m}$ and $1.73 \mathrm{~m}$, mutual impact range of spatial effect of tunnel face of left and right tunnel is 3 folds tunnel span. This research shall be referred to by similar Tunnel design and construction.
\end{abstract}

Keywords: Large span, mechanical characteristic, multi-arch tunnel, tunnel construction, weak surrounding rock.

\section{INTRODUCTION}

With increasing of China's traffic infrastructure construction in recent years, quantity of highway tunnel construction is increasing, new tunnel structure forms and related construction methods emerge in large number, due to restriction of topographic condition, multi-arch tunnel becomes the main form of middle and short distance expressway tunnel [1]. SHENG et al. showed that the distribution form of the plastic zones for the different execution procedures of the double and multi-arch tunnel $[2,3]$. Nevertheless, multi-arch tunnel structure has specificity and the design and construction technology is complicated, and is always the key research objective of tunnel engineering field of each country $[4,5]$. There are less engineering experiences for building large span double and multi arch tunnel in weak surrounding rock stratum, and the construction mechanical characteristic is unclear.

This paper relies on certain large span double arch tunnel works, and adopts large scale finite element analysis software to simulate construction process value of excavation form and method of actual work, to explore the variation rule of construction process to deformation of surrounding rock in the circumference of tunnel, ground surface settlement, stratum plastic zone distribution and tunnel supporting structure internal force, etc, which are compared with standard and actual monitored value result, to further optimize the detailed scheme, and the research result has guiding significance to similar works. This article content has no conflict of interest.

\section{MATERIALS AND METHODOLOGY}

\subsection{Materials}

The project is located in the border of Huangshan Mountain, Anhui Province of China, and is straight line large span multi-arch tunnel, the tunnel area belongs to construction erosion middle mountain area, the tunnel axial line sea level elevation is $3670.0 \mathrm{~m}-499.0 \mathrm{~m}$, the mountain relief is steep, the middle part is fluctuated and uneven with developed vegetation, inlet topographical slope angle is $35^{\circ}$, outlet section topographical slope angle is about $45^{\circ}$, the developed stratum in the tunnel site mainly includes: lower segment metamorphic sandstone of Daguyun Group of Jixianian System of mesoproterozoic erathem, landslide accumulation formation of quaternary of inlet section, the tunnel-through surrounding rock is of grade $\mathrm{V}$, the stability of surrounding rock is bad.

\subsection{Calculation Parameter and Model}

The physical and mechanics parameters of surrounding rock, sprayed concrete, anchor bolt and steel arch, etc are shown in Table $\mathbf{1}$. 
Table 1. Physical and mechanical parameters of surrounding rock and support.

\begin{tabular}{|c|c|c|c|c|c|}
\hline Material name & Elastic modulus MPa & Poisson ratio & $\begin{array}{c}\text { Specific gravity } \\
\mathrm{kN} / \mathrm{m}^{3}\end{array}$ & $\begin{array}{c}\text { Cohesion } \\
\mathrm{kPa}\end{array}$ & $\begin{array}{c}\text { Friction angel } \\
\text { Degree }\end{array}$ \\
\hline Rock and soil 2 & 150 & 0.3 & 21 & 200 & 30 \\
\hline $\begin{array}{l}\text { Pre-reinforcement } \\
\text { surrounding rock }\end{array}$ & 1000 & 0.2 & 24 & 500 & 45 \\
\hline Steel arch & 210000 & - & 78.5 & - & - \\
\hline Sprayed concrete & 21000 & 0.2 & 22 & 1500 & 45 \\
\hline Secondary lining & 29500 & 0.2 & 25 & 2000 & 55 \\
\hline
\end{tabular}

Newly built large span multi-arch tunnel construction adopts three heading construction sequence, tunnel span is $17.8 \mathrm{~m}$, tunnel burying depth is $48.5 \mathrm{~m}$, finite element model left and right calculation boundary is respectively taken as 5 folds of tunnel span.

In the finite element model, surrounding rock material characteristics of tunnel shall be considered as homogeneous elastic plastic body, Druker-Prage1 yield criterion is adopted, after the material enters into plastic status, the stress strain relationship shall be solved via incremental method of plastic theory.

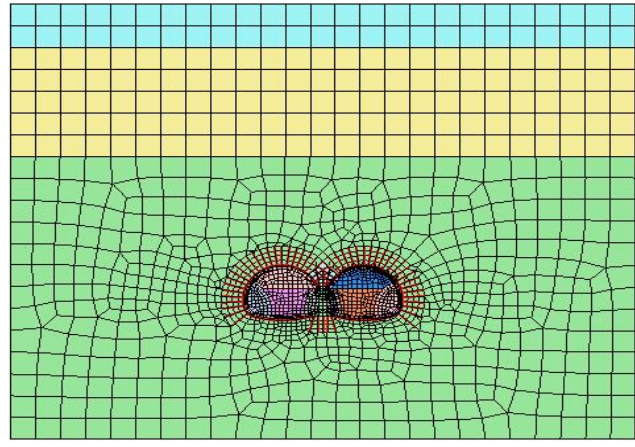

Fig. (1). Large span multi-arch tunnel computing grid model.

The surrounding rock, middle partition, sprayed concrete and secondary lining unit shall all be simulated by plane unit, anchor bolt shall be simulated by truss unit, steel arch and pilot tunnel temporary support shall all be simulated by girder unit [6-8]; related boundary displacement constraint is: left and right boundary horizontal constraint, lower boundary vertical constraint, upper boundary is free; the load calculation shall consider the deadweight of rock and earth mass, as well as excavation release load, the deadweight stress field $\mathrm{g}=9.8 \mathrm{~m} / \mathrm{s} 2$; without considering impact of construction stress, seism, and groundwater, etc to tunnel structure. The calculation model is shown in Fig. (1).

\section{RESULTS}

\subsection{Middle Pilot Tunnel Excavation and Preliminary Support}

According to three pilot tunnel construction scheme, at first the middle pilot tunnel excavation and middle partition (after excavation) preliminary support shall be conducted, the calculation model sketch is shown in Figs. (2) and (3), the calculation result deformation contour map is shown in Figs. (4) and (5).

The calculation result shows that, after excavation of middle pilot tunnel, arch top vertical max. Settlement displacement is $4.16 \mathrm{~mm}$, bottom max. Upheaval vertical displacement is $6.43 \mathrm{~mm}$, horizontal relative convergence displacement of side wall of two sides is $10.9 \mathrm{~mm}$. After middle pilot tunnel preliminary support and middle partition lining, arch top vertical accumulated settlement displacement is $4.66 \mathrm{~mm}$, bottom accumulated vertical displacement is $8.83 \mathrm{~mm}$, horizontal relative convergence displacement of side wall of two sides is $16.2 \mathrm{~mm}$. The calculation result shows that, at this time the support lining and surrounding rock are both at stable status.

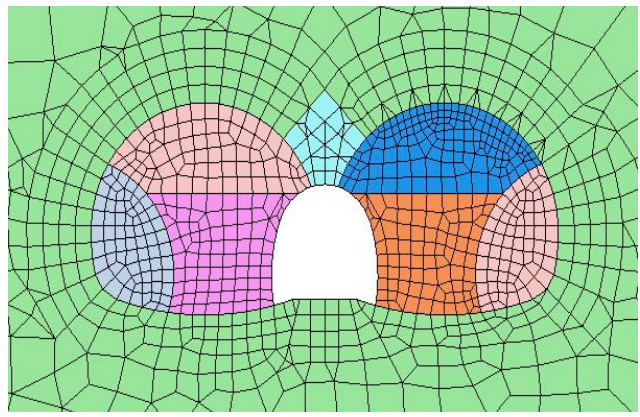

Fig. (2). Calculation model of middle pilot tunnel excavation.

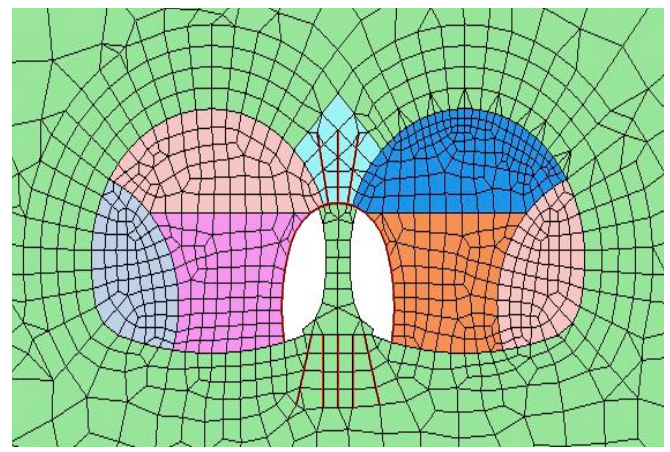

Fig. (3). Calculation model of middle partition support. 


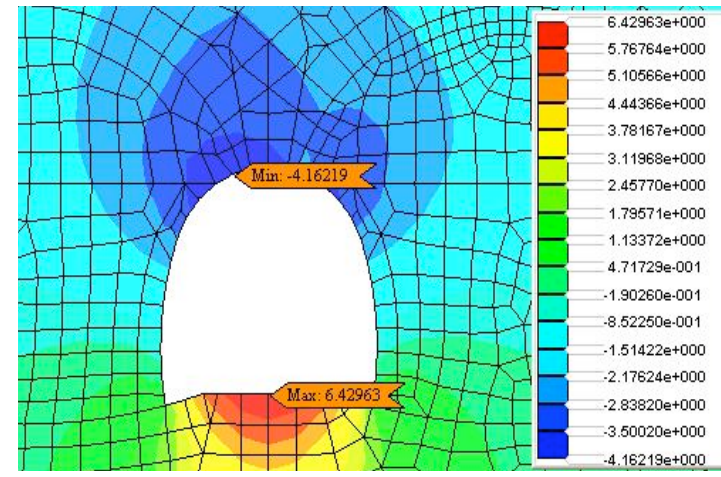

Fig. (4). Surrounding rock deformation chart after excavation of middle pilot tunnel (unit: $\mathrm{mm}$ ).

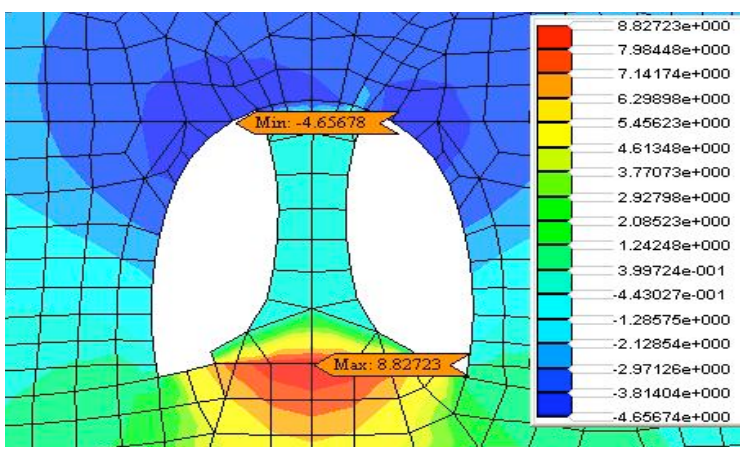

Fig. (5). Surrounding rock deformation chart after lining support of middle pilot tunnel (unit: $\mathrm{mm}$ ).

\subsection{Left and Right Pilot Tunnel Excavation and Prelimi- nary Support}

The construction procedure of left and right pilot tunnel excavation and preliminary support can be approx. analyzed as: left pilot tunnel excavation — preliminary support—right pilot tunnel excavation-preliminary support, the calculation model is shown in Figs. (6) to (9), and calculation result in Figs. (10) to (12).

The calculation result shows that, during left and right pilot tunnel excavation and preliminary support process, max. Vertical settlement displacement is at the top of right pilot tunnel, the value is $7.07 \mathrm{~mm}$, max. Horizontal convergence displacement is at left pilot tunnel side wall $9.33 \mathrm{~mm}$; max. Compressive stress of sprayed concrete of left pilot tunnel is at left pilot tunnel arch foot and is about $3.46 \mathrm{MPa}$, max. Compressive stress of sprayed concrete of right pilot tunnel is at right pilot tunnel arch foot and is about 1.163 MPa.

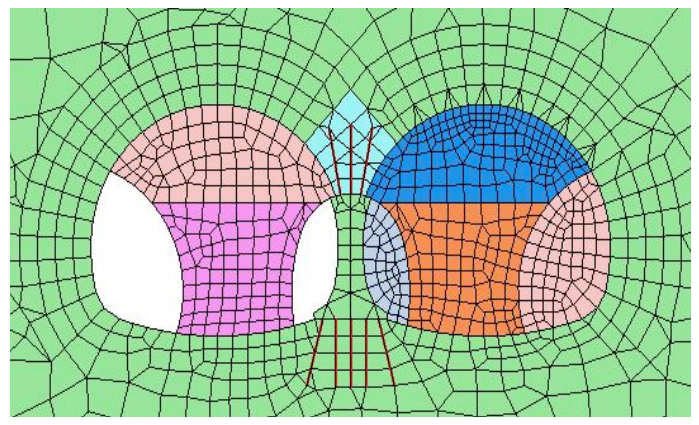

Fig. (6). Left pilot tunnel excavation calculation model.

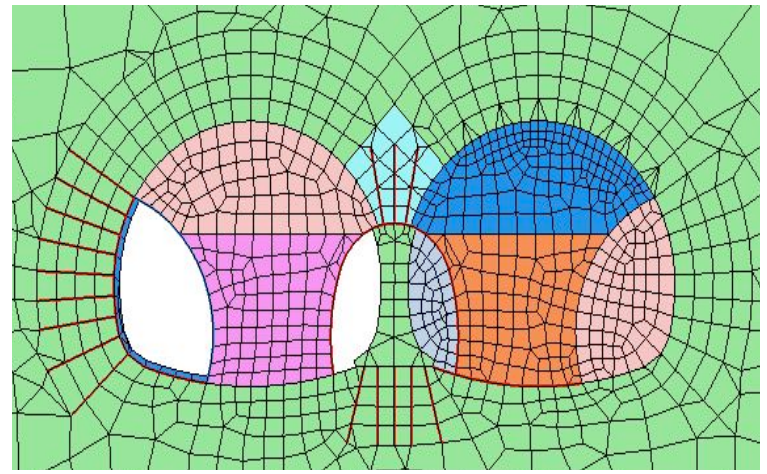

Fig. (7). Left pilot tunnel preliminary support calculation model.

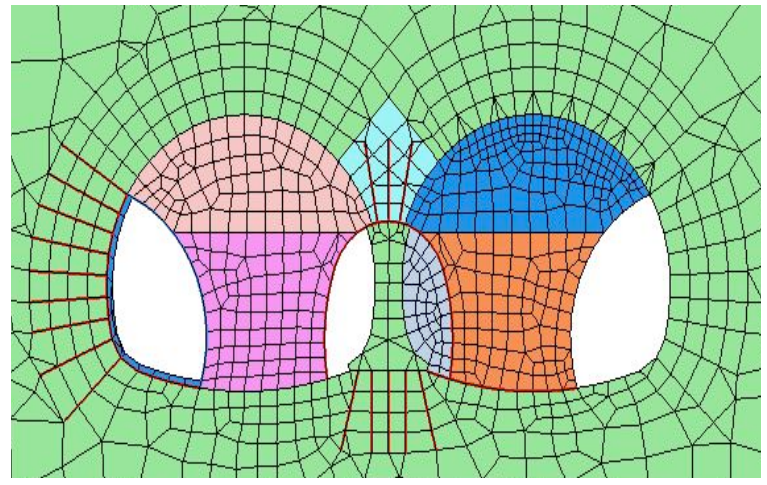

Fig. (8). Right pilot tunnel excavation calculation model.

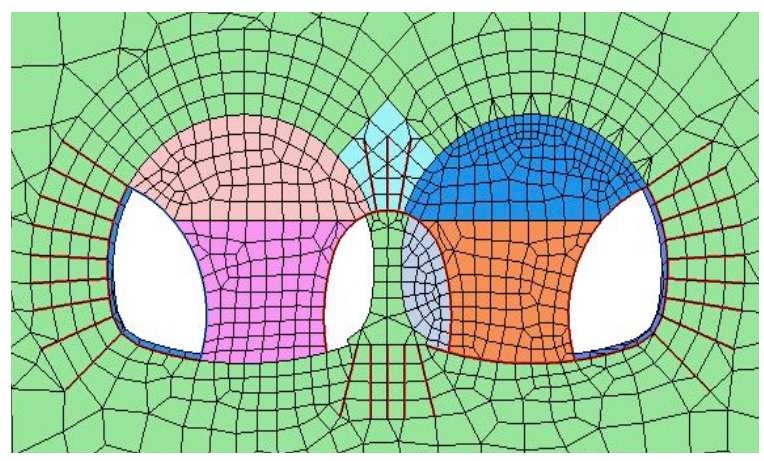

Fig. (9). Right pilot tunnel preliminary support calculation model.

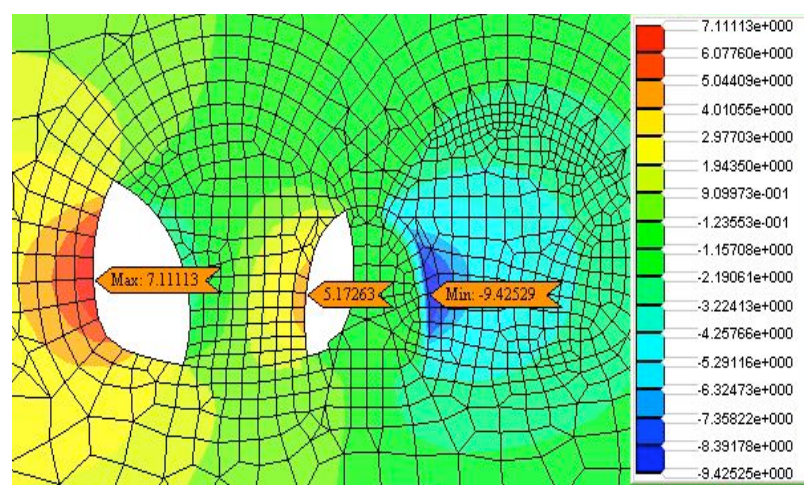

Fig. (10). Horizontal displacement cloud chart after excavation of left pilot tunnel (unit: $\mathrm{mm}$ ). 


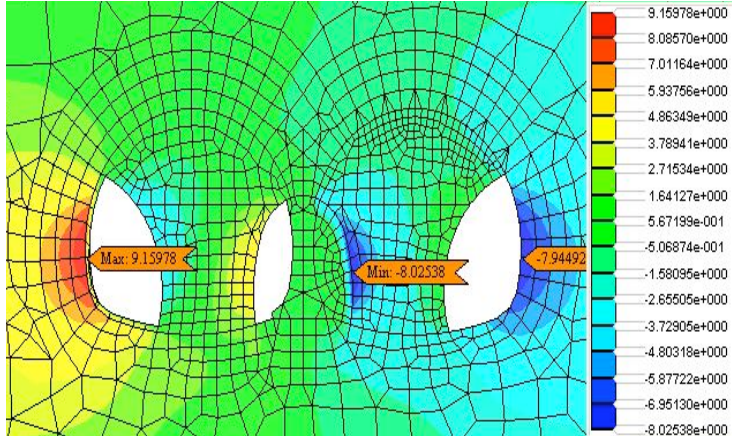

Fig. (11). Horizontal displacement cloud chart after excavation of right pilot tunnel (unit: $\mathrm{mm}$ ).

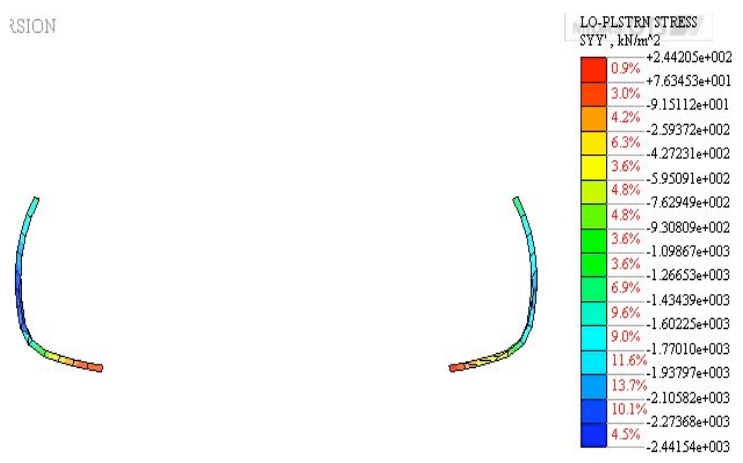

Fig. (12). Right pilot tunnel sprayed concrete stress (unit: MPa).

\subsection{Arch Excavation and Arch Preliminary Support of Left and Right Pilot Tunnel}

The calculation model of arch excavation and arch preliminary support of left and right pilot tunnel is shown in Figs. (6) to (9), and calculation result is in Figs. (17) to (20).

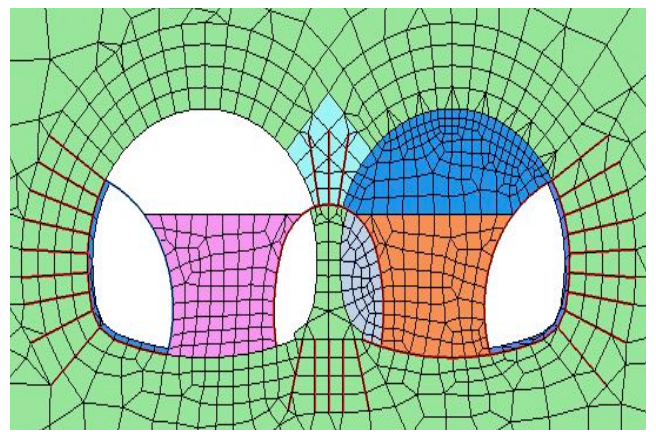

Fig. (13). Arch excavation of left pilot tunnel.

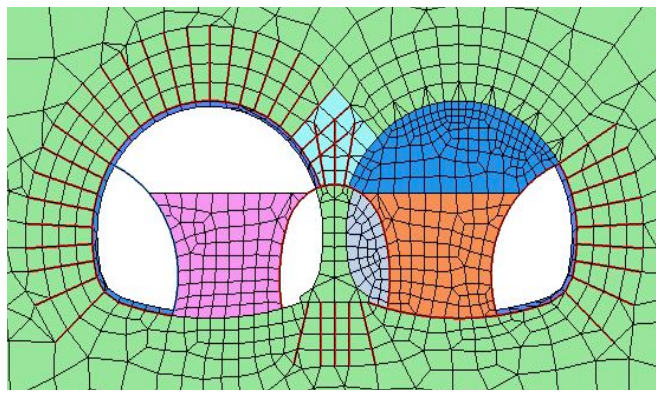

Fig. (14). Preliminary support of arch of left pilot tunnel.

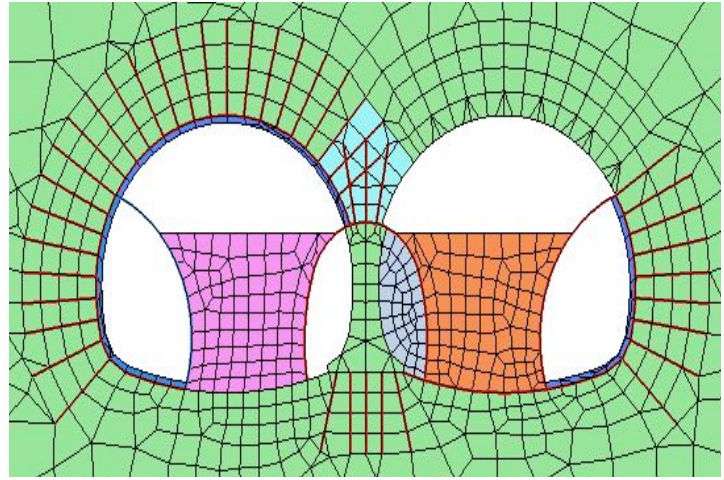

Fig. (15). Arch excavation of right pilot tunnel.

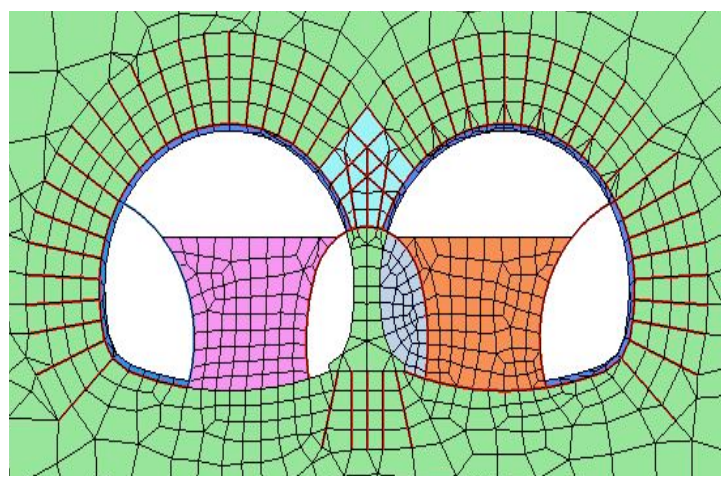

Fig. (16). Preliminary support of arch of right pilot tunnel.

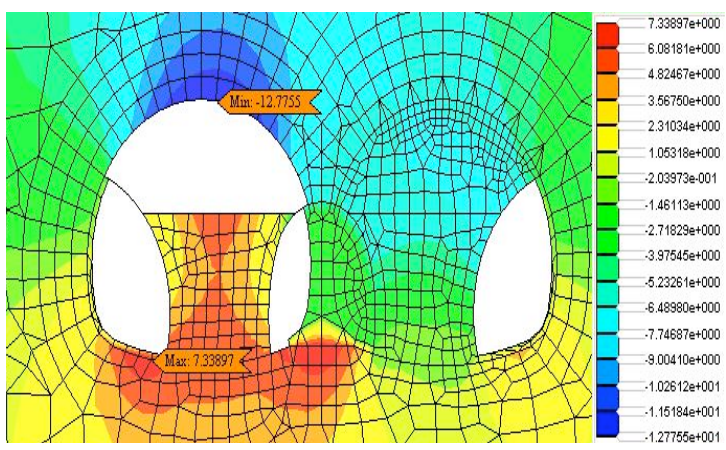

Fig. (17). Vertical displacement cloud chart after excavation of arch of left pilot tunnel (unit: $\mathrm{mm}$ ).

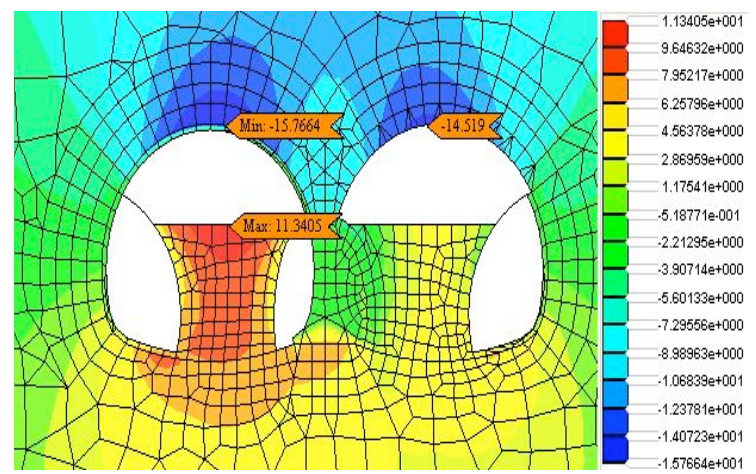

Fig. (18). Vertical displacement cloud chart after excavation of arch of right pilot tunnel (unit: $\mathrm{mm}$ ). 


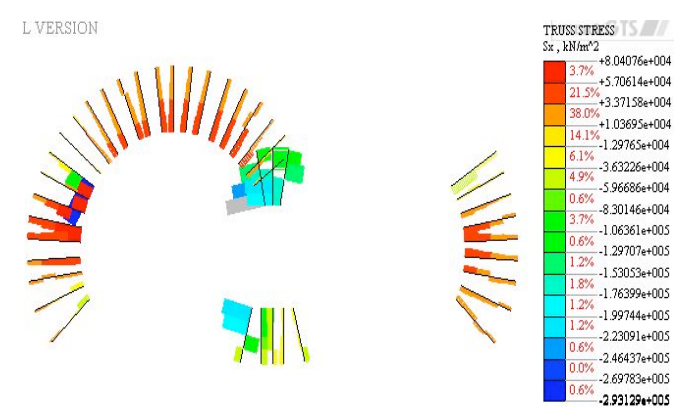

Fig. (19). Anchor bolt stress cloud chart after support of arch of left pilot tunnel (unit: MPa).

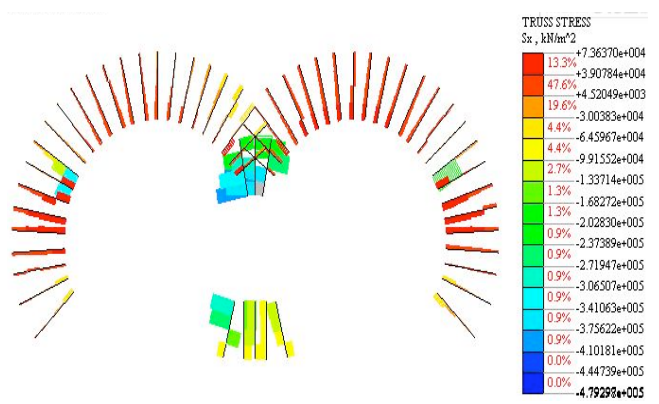

Fig. (20). Anchor bolt stress cloud chart after support of arch of right pilot tunnel (unit: $\mathrm{MPa}$ ).

The calculation result shows that, after excavation of arch of left pilot tunnel, vertical max. Displacement is at arch top of left pilot tunnel, the value is $12.78 \mathrm{~mm}$, max. Horizontal convergence displacement is at middle part of side wall of left pilot tunnel, the value is $9.43 \mathrm{~mm}$, max. Compressive stress of anchor bolt is at arch top, the value is $269.62 \mathrm{MPa}$.

After preliminary support of arch of left pilot tunnel, vertical max. Displacement is at arch top of left pilot tunnel with value of $15.1 \mathrm{~mm}$, max. Horizontal convergence displacement is at middle part of side wall of left pilot tunnel with value of $8.9 \mathrm{~mm}$, max. Compressive stress of anchor bolt is at arch top with value of $293.13 \mathrm{MPa}$.

After excavation of arch of right pilot tunnel, vertical max. Displacement is at arch top of left pilot tunnel with value of $15.76 \mathrm{~mm}$, vertical displacement of arch top of right pilot tunnel is $14.52 \mathrm{~mm}$, max. Horizontal convergence displacement is at middle part of side wall of right pilot tunnel with value of $9.26 \mathrm{~mm}$, max. Compressive stress of anchor bolt is at arch top with value of $449.84 \mathrm{MPa}$.

After preliminary support of arch of right pilot tunnel, vertical max. Displacement is at arch top of right pilot tunnel with value of $16.9 \mathrm{~mm}$, max. Horizontal convergence displacement is at middle part of side wall of right pilot tunnel with value of $8.74 \mathrm{~mm}$, max. Compressive stress of anchor bolt is at arch top with value of 479.3 $\mathrm{MPa}$.

Above calculation result shows that, the preliminary support structure is safe, and surrounding rock is at stable status.

\subsection{Bottom Excavation and Lining Support of Left and Right Pilot Tunnel}

The calculation model of bottom excavation and bottom preliminary support as well as secondary lining support of left and right pilot tunnel is shown in Figs. (21) to (24), and the calculation result is shown in Figs. (25) to (29).

The calculation result shows that, after bottom excavation of left pilot tunnel, max. Vertical displacement at arch top of right pilot tunnel is $18.11 \mathrm{~mm}$, horizontal convergence displacement of side wall of left and right pilot tunnel is respectively $8.98 \mathrm{~mm}$ and $9.1 \mathrm{~mm}$, max. Compressive stress of anchor bolt of arch top of middle pilot tunnel is $491.47 \mathrm{MPa}$, max. Compressive stress of anchor bolt of bottom of middle wall is $479.25 \mathrm{MPa}$;

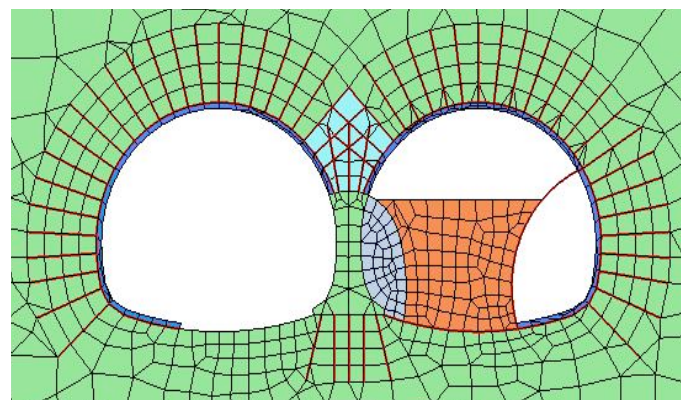

Fig. (21). Bottom excavation of left pilot tunnel.

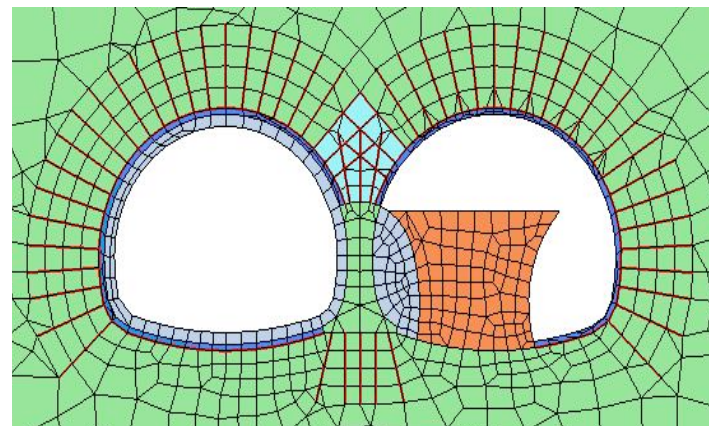

Fig. (22). Secondary lining of left pilot tunnel.

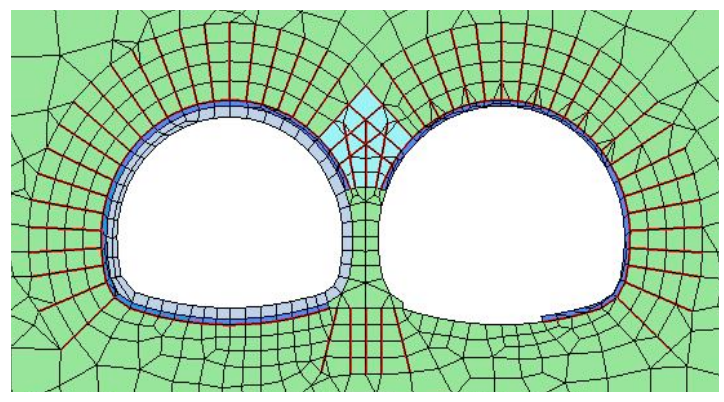

Fig. (23). Bottom excavation of right pilot tunnel.

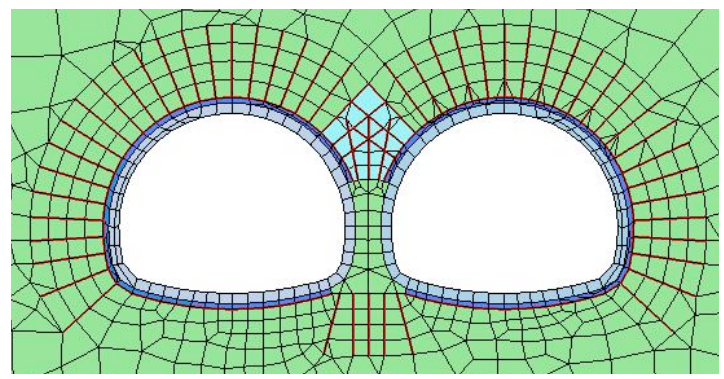

Fig. (24). Secondary lining of right pilot tunnel. 


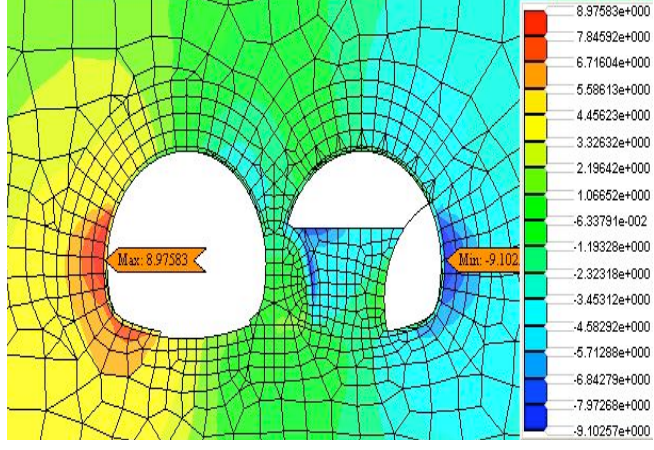

Fig. (25). Horizontal displacement cloud chart after bottom excavation of left pilot tunnel.

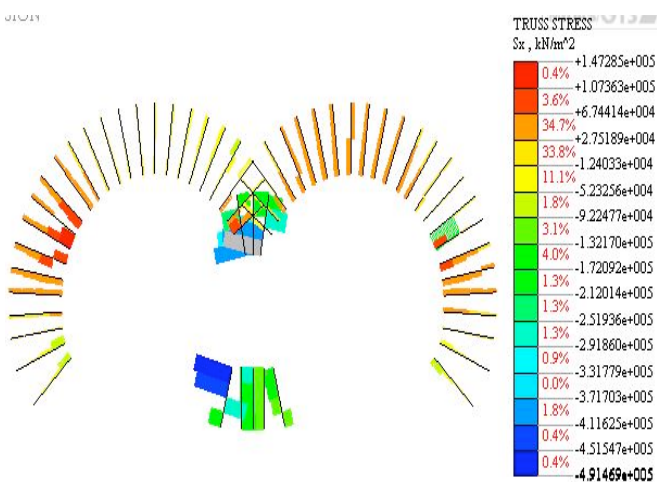

Fig. (26). Anchor bolt stress cloud chart after bottom excavation of left pilot tunnel.

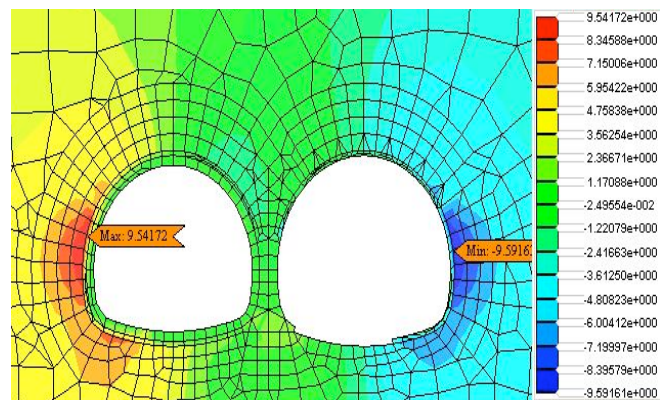

Fig. (27). Horizontal displacement cloud chart of surrounding rock after excavation of bottom of right pilot tunnel.

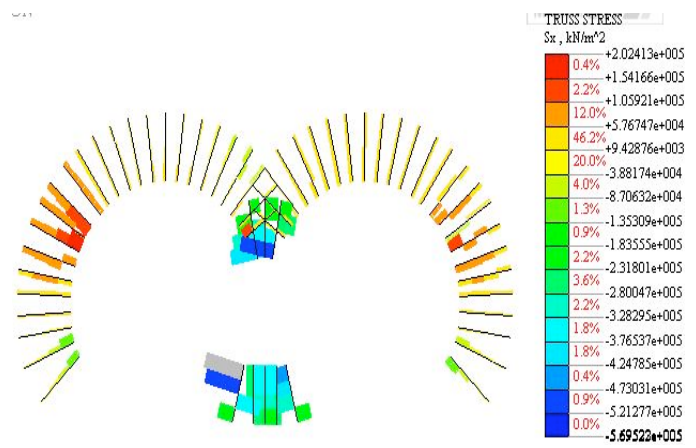

Fig. (28). Anchor bolt stress cloud chart after bottom excavation of right pilot tunnel.

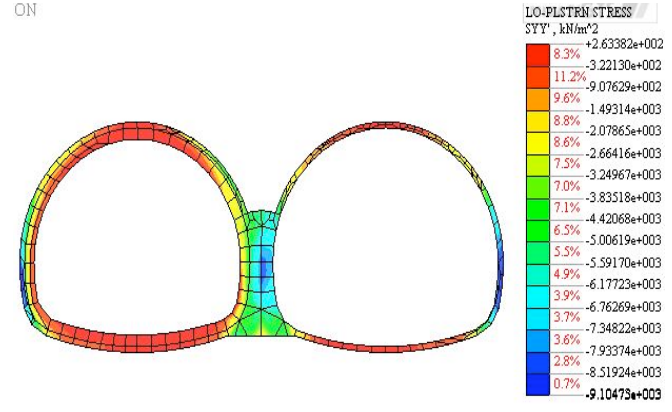

Fig. (29). Lining structure stress cloud chart after bottom support of right pilot tunnel.

After secondary lining of left pilot tunnel, max. Vertical displacement of right pilot tunnel is $19.16 \mathrm{~mm}$, max. Vertical displacement of arch top of secondary lining of left pilot tunnel is $0.76 \mathrm{~mm}$, max. Compressive stress of anchor bolt is $541.07 \mathrm{MPa}$ at bottom of middle wall, max. Compressive stress in the lining of middle wall is at left wall foot and is 9.94 $\mathrm{MPa}, \max$. Compressive stress in the secondary lining is $0.54 \mathrm{MPa}$;

After bottom excavation of right pilot tunnel, max. Vertical displacement of arch top of right pilot tunnel is $18.64 \mathrm{~mm}$, horizontal convergence displacement of side wall of left and right pilot tunnel is respectively $9.54 \mathrm{~mm}$ and $9.59 \mathrm{~mm}$, max. Compressive stress of anchor bolt of arch top of middle pilot tunnel is $494.84 \mathrm{MPa}$, and max. Compressive stress of anchor bolt of bottom of middle wall is $569.52 \mathrm{MPa}$.

After secondary lining of right pilot tunnel, max. Vertical displacement of arch top of right pilot tunnel is $19.45 \mathrm{~mm}$, max. Vertical displacement of arch top of secondary lining of left pilot tunnel is $2.57 \mathrm{~mm}$, max. Compressive stress of anchor bolt is $591.1 \mathrm{MPa}$ at bottom of middle wall, anchor bolt stress at top of middle wall is $496.25 \mathrm{MPa}$, max. Compressive stress in the lining of middle wall is $10.34 \mathrm{MPa}$ at left foot, the most unfavorable position of force bearing in the secondary lining is at lining top of middle partition wall and two sides area of middle wall foot, and max. Compressive stress of left side of middle wall top is $4.02 \mathrm{MPa}$;

Distribution of plastic zone of surrounding rock shows that, max. Plastic zone depth at upper side of arch top of left and right pilot tunnels is $1.23 \mathrm{~m}$, plastic zone depth of inverted arch bottom is $2.74 \mathrm{~m}$, plastic zone depth in the middle part of side wall of left and right pilot tunnels is $0.87 \mathrm{~m}$, max. Compressive stress of surrounding rock of top of middle wall is $2.33 \mathrm{MPa}$, max. Shear stress is $0.77 \mathrm{MPa}$, which are all lower than yield strength of surrounding rock after reinforcement.

\section{CONCLUSION}

The elastic plastic finite element method is adopted to analyze tunnel surrounding rock deformation, anchor bolt force bearing, preliminary support and secondary lining internal force mechanical characteristic during construction process of large span multi arch tunnel work, to derive following main conclusions:

Repeatedly disturbance of middle pilot tunnel excavation and subsequent excavation support shall easily reduce 
strength of surrounding rock at top of middle wall and middle line range of arch top of left and right pilot tunnels, and incur uneven force bearing of supporting structure, therefore, prior to excavation of middle pilot tunnel, the surrounding rock of tunnel top shall be pre-grouting reinforced, to improve integrated strength of surrounding rock of arch top;

Deformation during tunnel excavation supporting process shows that, max. Accumulated settlement displacement of tunnel arch top is $19.45 \mathrm{~mm}$, max. Accumulated settlement displacement at the margin in tunnel arch top is $2.57 \mathrm{~mm}$, max. Horizontal convergence displacement of side wall of left and right pilot tunnels is $9.71 \mathrm{~mm}$, after middle wall lining supporting for middle pilot tunnel excavation, max. Vertical upheaval displacement of bottom of middle wall is 8.82 $\mathrm{mm}$, above displacements can all be in the control range and satisfy design requirement;

During preliminary support construction of side wall of two sides of tunnel, the most unfavorable force bearing position is at left and right arch foot, the calculation result shows that, construction of excavation of right pilot tunnel disturbs the left pilot tunnel, incurring stress relaxation of partial area, e.g., internal force of sprayed concrete of preliminary support of left pilot tunnel is greater than that of right pilot tunnel, therefore it is necessary to at first increase strength of preliminary support of arch foot of two sides, to avoid loosening area due to unstability of surrounding rock.

After preliminary support of left pilot tunnel, variation of plastic zone of surrounding rock shall be closely observed, especially the double and multi arch tunnel shall incur eccentric compression due to uneven release of stress of surrounding rock, distribution of plastic zone of surrounding rock shows that, max. plastic zone vertical depth at arch top of left and right pilot tunnels is respectively $1.23 \mathrm{~m}$ and $2.06 \mathrm{~m}$, vertical depth of plastic zone of inverted arch bottom is respectively $2.74 \mathrm{~m}$ and $3.37 \mathrm{~m}$, radial depth of plastic zone of middle part of side wall of left and right pilot tunnels is respectively $0.87 \mathrm{~m}$ and $1.73 \mathrm{~m}$, it can be seen that, prior to excavation of surrounding rock of lower terrace of right pilot tunnel, it is feasible and reasonable to at first conduct lift pilot tunnel secondary lining and then conduct subsequent excavation support, and mutual impact range of spatial effect of face of left and right tunnels is 3 folds tunnel span.

\section{CONFLICT OF INTEREST}

The authors confirm that this article content has no conflict of interest.

\section{ACKNOWLEDGEMENTS}

This work was supported by the national natural science foundation of china (51208069), the applied basic research project of Sichuan Province (2014JY0083), the postdoctoral foundation of china (2013M531978), and the State Key Laboratory of Geohazard Prevention and Geoenvironment Protection (SKLGP2012Z005).

\section{REFERENCES}

[1] X. L. Zhang and Y. Y. Jiao, "Simulation of failure process of jointed rock", Journal of Central South University of Technology, vol. 15, pp. 888-894, June 2008.

[2] Y. S. Shen, Y. G. Zhao, H. X. Zhang, W. Guo, Z. Y. Lin, Y. M. Wan, H. Q. Zhang, and Z. Li, "Numerical analysis of elastoplastic finite element in construction of twin-arch tunnel", Chinese Journal of Rock Mechanics and Engineering, vol. 23, pp. 49464951, December 2004.

[3] Z. C. Sun, "Construction technology for double-arched tunnel with superposed partition wall", Tunnel Construction, vol. 28, pp. 460-464, April 2008.

[4] C. B. Xu and C. C. Xia, "Optimum analysis of construction scheme of multi arch tunnel with eight traffic lanes", Chinese Journal of Rock Mechanics and Engineering, vol. 28, pp. 66-73, January 2009.

[5] W. Q. Ding and X. X. Wang, "Optimal analysis of construction schemes for shallow large span Longshan twin tunnel", Chinese Journal of Rock Mechanics and Engineering, vol. 24, pp. 40424047, November 2005.

[6] J. Wang, Z. L. Liu, and Y. Chen, "Comparative Analysis of Economic Efficiency of Grain Storage by Solar Absorption Refrig eration", AISS: Advances in Information Sciences and Service Sciences, vol. 4, no. 14, pp. 341-348, 2012. doi: 10.4156/AISS.vol4.issue14.42

[7] J. F. Lu, Y. Y. Jia, and B. X. Liu, "Impact of Orthogonal Undercrossing Newly-built tunnel Adjacent Construction on the Safety of Existing Municipal Tunnel", Disaster Advances, vol. 5, pp. 756-761, October 2012.

[8] F. Huang, "Upper bound analysis of collapsing mechanism of surrounding rock and rock bolt supporting structures for tunnels", Disaster Advances, vol. 5, pp. 756-761, October 2012. 